\title{
Effect of taste preexposure on taste and odor aversions
}

\author{
MARK D. HOLDER, MATTHEW LEON, RAZ YIRMIYA, and JOHN GARCLA \\ University of California at Los Angeles, Los Angeles, California
}

\begin{abstract}
Thirsty Sprague-Dawley rats drank flavored water in a wind tunnel prior to lithium-induced toxicosis. Flavors were presented for $5 \mathrm{~min}$; $30 \mathrm{~min}$ later a toxin, lithium chloride, was injected. After the rats had recovered, subsequent aversions to the taste and the odor were assessed separately. In Experiment 1, extensive preexposure to the taste component of the flavor attenuated neophobia to the flavor and the subsequent taste aversion. However, the subsequent odor aversion was unaffected. Experiment 2 partially replicated the results of Experiment 1 and showed that, in a situation in which only taste-potentiated odor aversions are usually found, nonpotentiated aversions were evident. Experiment 3 found that, in addition to attenuating taste aversions, taste preexposure enhances the capacity of rats to learn nonpotentiated odor aversions. The results are interpreted with a neural-based model of conditioned flavor aversions.
\end{abstract}

After a specific taste is followed by delayed illness, animals learn to avoid that taste. In a similar experimental design, after a specific odor is followed by delayed illness, animals often do not learn a strong odor aversion. However, when the odor and taste are presented together and followed by delayed illness, the taste enhances the odor such that the odor alone is subsequently strongly avoided (e.g., Palmerino, Rusiniak, \& Garcia, 1980; Rusiniak, Hankins, Garcia, \& Brett, 1979). The development of taste aversions and these taste-potentiated odor aversions are interrelated. For example, as taste intensity increases, the strength of the subsequent aversion to both the taste and odor increases (Rusiniak et al., 1979; Spear \& Kucharski, 1984a, 1984b). Odor alone is more readily associated with immediate footshock than with delayed illness. However, when taste is added to drinking water, odor-illness conditioning is facilitated when a toxin is used, but the same taste attenuates conditioning to that same odor when shock is used (Rusiniak, Palmerino, Rice, Forthman, \& Garcia, 1982). This suggests that when an odor is presented with a taste, the odor behaves like a taste.

Several studies have indicated that the development of odor aversions and taste aversions are partially independent. For example, odor aversions can be eliminated by changing the delay between odor and taste, but taste aversions remain unaffected (Coburn, Garcia, Kiefer, \& Rusiniak, 1984; Holder \& Garcia, in press). Similarly, increases in odor intensity result in increases in the strength of the odor aversion but not of the taste aversion (Holder $\&$ Garcia, in press). Early experience with flavors increases rats' ability to learn odor aversions, but taste aver-

This research was supported by a National Institutes of Health grant awarded to John Garcia and a Natural Sciences and Engineering Research Council grant awarded to Mark D. Holder. Address all correspondence to Mark D. Holder, who is now at the Department of Psychology, Memorial University of Newfoundland, St. John's, Newfoundland A1B 3X9, Canada. sion learning is not changed (Rusiniak, Garcia, Palmerino, \& Cabral, 1983). Odor and taste aversions can also be separated neuroanatomically. Lesions of the gustatory neocortex disrupt taste aversions but not taste-potentiated odor aversions (Kiefer, Rusiniak, \& Garcia, 1982). Additionally, when novocaine is applied directly to the amygdala $30 \mathrm{~min}$ before a flavor is presented, taste-potentiated odor aversions, but not taste aversions, are attenuated (Bermudez-Rattoni, Rusiniak, \& Garcia, 1983).

Previous work has indicated that prior experience with a taste alone attenuates aversion learning to that taste (e.g., Kalat \& Rozin, 1973; Revusky \& Bedarf, 1967). The three experiments reported here examined the effect of preexposure of taste on subsequent flavor aversion learning. In order to have strict control over the presentation of the odor, rats were trained and tested in an olfactometer, a "wind tunnel" apparatus designed to present discrete odor stimuli. A constant airstream, into which odor was introduced for $5 \mathrm{~min}$, moved through a chamber housing a rat. At the upwind end of the chamber, a waterspout was made available so that the rat could lick water during each trial. After habituation to the apparatus and a restricted drinking schedule, odor and taste were presented, followed $30 \mathrm{~min}$ later by an injection of isotonic lithium chloride $(\mathrm{LiCl})$ or isotonic saline.

\section{EXPERIMENT 1}

The effects of taste preexposure on the odor and taste components of a conditioned flavor aversion were assessed. Half the rats were given previous experience with the taste. There was no control group that received odor without taste before the $\mathrm{LiCl}$. Using the same apparatus and stimuli used here, and similar parameters and similarly aged rats, several experiments in our laboratory have shown that this procedure produces little or no odor aversion unless taste is presented with odor during acquisition (Coburn et al., 1984; Holder \& Garcia, in press). 


\section{Method}

Apparatus and Subjects. The subjects were 32 male SpragueDawley rats, weighing 200-309 g. The rats had free access to dry food in their individual home cages, but limited access to water, as described below. A 14 h:10 h light:dark cycle was always in effect, and daily sessions began in the middle of the light phase of the cycle.

The rats were habituated, trained, and tested in an olfactometer. This apparatus consisted of two $18.5 \times 6.5 \times 12.5 \mathrm{~cm}$ Plexiglas chambers, at one end of which the rat could poke its muzzle through an opening into a smaller $3 \times 5 \times 4 \mathrm{~cm}$ chamber to lick fluid from a stainless steel spout. Access to water, always distilled, could be prevented by turning the spout away from the rat. For each box, compressed air was first forced through a 13-in. column of activated charcoal and then through an 8-in. column of Drierite (anhydrous $\mathrm{CaSO}_{4}$ ) before being bubbled through either pure Schilling almond extract (the odor) or distilled water (unscented air). Solenoidoperated valves determined whether the odor or unscented air was presented. A constant airstream flowed from the smaller to the larger chamber so that a virtual square wave of odor could be presented to the drinking rat. The odor was cleared within $15 \mathrm{sec}$ by an exhaust fan, attached to the back of each chamber, that continually evacuated air from the room; we could detect no odor leakage into the room housing the apparatus. Except for the 2 rats being run, all rats were kept in an adjoining room further isolated from the experimental odors.

Procedure. The rats were assigned randomly to one of two equalsized groups that differed on whether a taste was preexposed or novel. The preexposed group received the sweet taste $(.1 \% \mathrm{w} / \mathrm{v}$, sodium saccharin in distilled water) for 30 days prior to conditioning. The taste was presented in their drinking water, which was always available. The nonpreexposed group received unflavored water during this 30 -day period.

After the $\mathbf{3 0}$ days of preexposure to sweet or unflavored water, the rats were habituated to the olfactometer for 9 days. The rats started each daily session thirsty (they were given access to tap water for 20 min each day in their home cages after being run in the olfactometer). For the first 7 days, habituation consisted of one 6min trial; for the last 2 habituation days, and all remaining days, trials were $5 \mathrm{~min}$. On the last 2 habituation days, the preexposed groups received sweet water in the olfactometer, and the nonpreexposed groups continued to receive unflavored water.

After the last habituation day, there was a single acquisition day on which each rat had $5 \mathrm{~min}$ access to the sweet water while the odor was presented. Equal numbers of preexposed and nonpreexposed rats were assigned to two conditions on the basis of similar average water consumption on the last day of habituation. The conditions differed in whether the rats were injected with $.15 \mathrm{M} \mathrm{LiCl}$ or $.15 \mathrm{M}$ saline. Injections ( $2 \%$ body weight) were given intraperitoneally $30 \mathrm{~min}$ after presentation of the flavor. To identify each group, PreX and Nov were used to denote whether the taste had been preexposed or was novel on the acquisition day, and $\mathrm{LiCl}$ and Sal were used to indicate the substance injected. For example, Group PreX-LiCl represents the rats preexposed to the taste and injected with $\mathrm{LiCl}$, and Group Nov-Sal represents the rats not preexposed to the taste and injected with isotonic saline.

Following acquisition, the rats were returned to the habituation schedule for 2 days. The 3rd postacquisition day was an odor test; odor was presented with plain water during the 5-min trial. After 1 more day of habituation, there was a taste test; taste and unscented air were presented during the 5-min trial.

Data analysis. During each trial, the volume of fluid consumed was recorded for each rat. To analyze the acquisition, taste test, and odor test data, 2 (preexposed vs. novel) $\times 2$ ( $\mathrm{LiCl}$ vs. saline) analyses of variance (ANOVAs) were used. The ANOVAs treated rats as a random factor and the other factors as fixed.

\section{Results and Discussion}

Figure 1 shows consumption during acquisition and during the odor and taste tests for each group. During acquisition, the rats preexposed to the taste consumed more

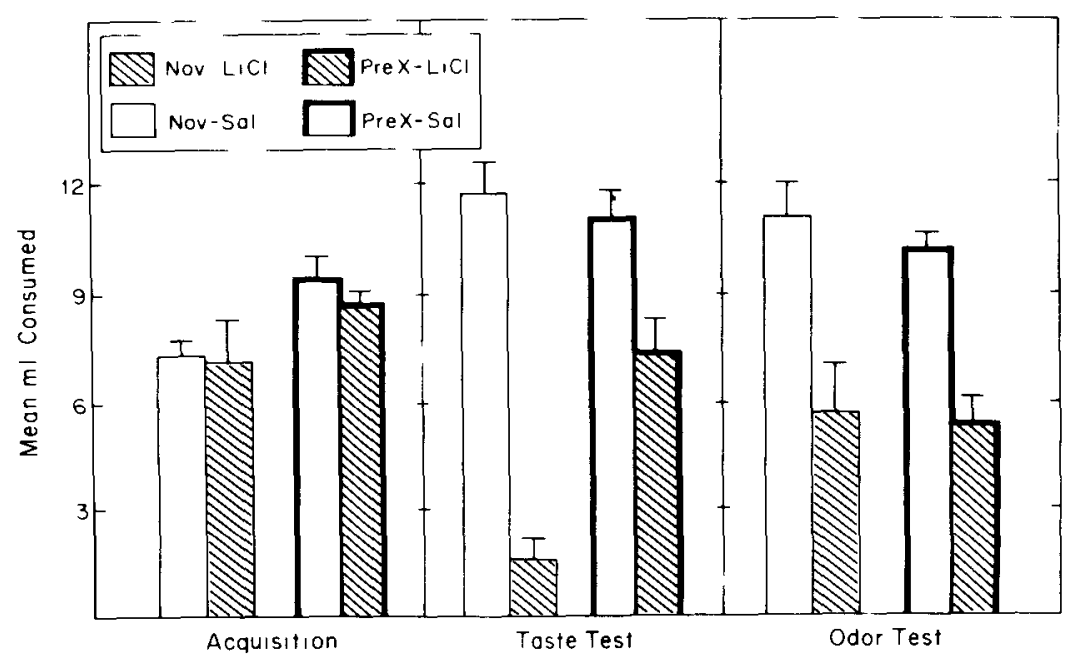

Figure 1. Experiment 1: Mean consumption during acquisition and during taste and odor tests is shown for each of the four groups. During acquisition, the two groups that were familiar with the taste (Groups PreX-LiCl and PreX-Sal) consumed slightly more. During the taste test, both groups that received LiCl after the fiavor (Groups PreX-LiCl and Nov-LiCl) showed a taste aversion, but the aversion was stronger when the taste was novel (Group Nov-LiCl). During the odor test, Groups PreX-LiCl and Nov-LiCl showed equally strong aversions as compared with the groups given saline after the flavor (Groups PreX-Sal and Nov-Sal). (Error bars represent standard errors.) 
than the rats not preexposed $[F(1,28)=4.44, p<.05]$. This difference probably resulted from the preexposed rats' being less neophobic to the taste. The difference indicated that the preexposure manipulation was effective.

When taste was tested, the groups injected with $\mathrm{LiCl}$ consumed less than those injected with saline $[F(1,28)=$ $71, p<.001]$. The preexposure effect was demonstrated by the fact that Group PreX-LiCl's taste aversion was less than that of Group Nov-LiCl. This conclusion was confirmed by a significant substance injected $\times$ prior exposure interaction $[F(1,28)=14.6, p<.001]$.

During the odor test, the groups injected with $\mathrm{LiCl}$ consumed less than those injected with saline $[F(1,28)=71$, $p<.001]$. However, the strength of the odor aversion was the same for both groups injected with $\mathrm{LiCl}$. The absence of a preexposure effect was supported by the lack of both a prior experience effect $[F(1,28)<1]$ and a prior experience $\times$ substance injected interaction $[F(1,28)<1]$. The absence of any difference between the odor aversions of Groups $\mathrm{PreX}-\mathrm{LiCl}$ and $\mathrm{Nov}-\mathrm{LiCl}$ was not obscured by floor effects. Although both groups drank less than the control groups injected with saline, they did consume an average of over $5 \mathrm{ml}$ during the odor test.

As expected on the basis of earlier work (e.g., Kalat \& Rozin, 1973; Revusky \& Bedarf, 1967), taste preexposure attenuated the strength of the taste aversion. However, taste preexposure had no effect on the strength of the odor aversion. Odor aversions are sensitive to other preexposure effects. For example, when an odor is presented before it is paired with illness, the subsequent strength of the odor aversion is attenuated (Palmerino, Rusiniak, Forthman, \& Garcia, 1981; Westbrook, Bond, \& Feyer, 1981).

The order of the taste and odor testing was confounded in this experiment; all rats were tested with odor first, to avoid problems associated with odor leakage. If half of the rats were tested with taste at the same time the others were tested with odor, the rats tested with taste might possibly have smelled lingering odor from the odor testing. Testing all rats with odor first eliminated this possibility. The role of this confound is probably trivial here. Using similar procedures, Lett (1984a) and Palmerino (1979) found that extinction of one component of a flavor aversion did not affect the strength of the other component measured later. Furthermore, the critical comparisons in the present experiments involved the strength of the odor aversions, and all comparisons were between groups that had the same prior test experience.

\section{EXPERIMENT 2}

Experiment 1 showed that taste preexposure attenuated taste aversion but not odor aversion. However, the nature of the odor aversion remained in doubt. Without a control for the strength of the odor aversion when the odor was presented during acquisition without a taste, the degree to which the odor aversion reflected a straight odor aversion or a taste-potentiated odor aversion was not clear.
Although our earlier work (Coburn et al., 1984; Holder \& Garcia, in press) had suggested that Experiment 1 should have produced little or no straight odor aversion, the taste-potentiated odor aversions observed in these earlier studies were stronger than that observed in Experiment 1 . Furthermore, the taste used in these earlier studies was never preexposed. Therefore, Experiment 2 partially replicated Experiment 1 but included a control for the development of odor aversions in the absence of taste.

\section{Method}

Apparatus and Subjects. The subjects were 36 male SpragueDawley rats, weighing 196-319 g. The rats were housed and maintained as described in Experiment 1. The olfactometer described in Experiment 1 was used for all training and testing.

Procedure. Because the procedure was similar to that of Experiment 1 , only the differences will be emphasized here. The rats were habituated to the olfactometer for 9 days. All rats were then preexposed to the sweet taste during the daily 5 -min trials in the olfactometer for 3 days prior to acquisition. Unlike Experiment 1, there were no preexposure days in the home cages.

After the last preexposure day, the rats were assigned to four groups ( 9 rats per group) so that average consumption on the last preexposure day was similar for all animals within a group. The day after the last preexposure day was a single acquisition day consisting of a 2 (odor vs. odor/taste) $\times 2$ ( $\mathrm{LiCl}$ vs. saline) design. Groups $\mathrm{O}-\mathrm{LiCl}$ and $\mathrm{O}-\mathrm{Saline}$ were presented with the odor and plain water (i.e., no taste) followed $30 \mathrm{~min}$ later by $\mathrm{LiCl}$ or saline, respectively. Groups OT-LiCl and OT-Saline were presented with the odor and taste together followed $30 \mathrm{~min}$ later by $\mathrm{LiCl}$ or saline, respectively.

Following acquisition, the rats were returned to the habituation schedule for 1 day and then tested for odor and taste aversions as described in Experiment 1.

Data analysis. Data collection and analysis were similar to those in Experiment 1. To analyze the acquisition, taste test, and odor test data, 2 (O vs. OT) $\times 2$ ( $\mathrm{LiCl}$ vs. saline) ANOVAs were used.

\section{Results and Discussion}

Figure 2 shows consumption during acquisition and during the odor and taste tests for each group. During acquisition, all groups consumed similar amounts of solution. There were no significant main effects or interactions $\left[F_{\mathrm{s}}(1,32) \leq 1.2, p \mathrm{~s} \geq .28\right]$. The groups also consumed similar amounts during the taste test. No significant main effects or interactions were found $[F \mathrm{~s}(1,32)$ $\leq 1.67, p s \geq .21]$. The groups injected with saline consumed relatively high amounts of sweet water because they were not made sick and therefore did not develop a taste aversion. The groups injected with $\mathrm{LiCl}$ consumed equally high amounts of sweet water, probably because, although they were made sick, the taste preexposure attenuated their learning of a taste aversion.

When odor was tested, the groups injected with $\mathrm{LiCl}$ consumed less than those injected with saline $[F(1,32)=$ $34.7, p<.001]$. There was no evidence of a specific taste-potentiated odor aversion; the strength of the odor aversion was the same for both Group OT-LiCl and Group O-LiCl. The absence of a potentiation effect was supported by the lack of both an OT versus $O$ effect $[F(1,32)<1]$ and an interaction between whether or not 


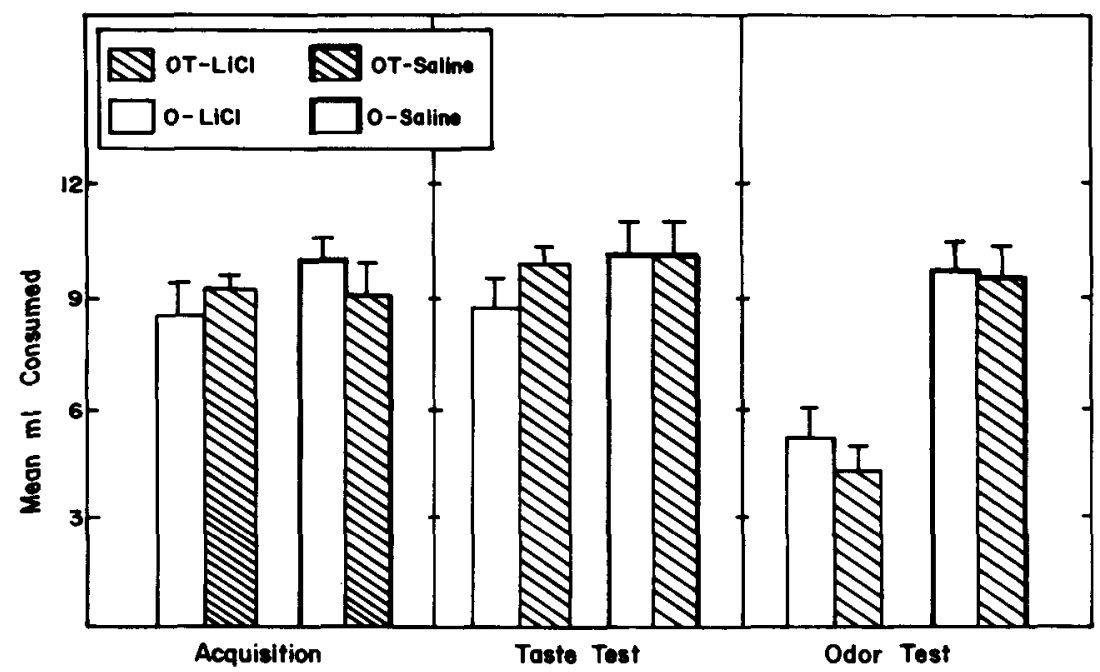

Figure 2. Experiment 2: Consumption during acquisition and during taste and odor tests is shown for the four groups. During acquisition and the taste test, all groups consumed similar amounts. There was no evidence of taste aversions during the taste test. During the odor test, the groups in which, during acquisition, illness had been induced after the odor and taste (Group OT-LCC) or the odor alone (Group O-LCI) showed equally strong aversions. The groups given saline after the odor and taste (Group OT-Saline) or odor only (Group 0-Saline) did not show aversions. (Error bars represent standard errors.

taste was presented during acquisition and the substance injected $[F(1,32)<1]$. As in Experiment 1 , the absence of differences between the odor aversions of Groups OT$\mathrm{LiCl}$ and $\mathrm{O}-\mathrm{LiCl}$ is probably not attributable to floor effects. During the odor test, both groups drank about $5 \mathrm{ml}$.

\section{EXPERIMENT 3}

In Experiment 2, a method that typically does not produce straight odor aversions (Coburn et al., 1984; Holder \& Garcia, in press) nevertheless did so. The apparatus was identical to that used in these earlier studies, and most of the parameters used, such as age and type of rat, taste stimulus, odor stimulus, and injection, were the same or very similar. One obvious difference between Experiment 2 and the earlier work was that the taste was preexposed. Previous work has shown that prior experience with flavors, other than those paired with illness, can enhance rats' ability to learn straight odor aversions (Rusiniak et al., 1983). Perhaps the taste preexposure used in the present work similarly enhanced the animals' capacity to form odor aversions without tastes. Taste preexposure could enhance straight odor aversions in another way. Exteroceptive stimuli paired with tastes can potentiate odor aversions when these stimuli are presented with the odors prior to illness (Holland, 1983). Perhaps when the taste was preexposed in the olfactometer, aspects of the olfactometer were associated with the taste. When the rat was placed in the olfactometer during acquisition, these aspects of the olfactometer evoked a representation of the taste, and this representation potentiated the odor aversion (see Holland, 1981, 1983; Holland \& Forbes, 1982).

Experiment 3 tested the possibility that taste preexposure enhances straight odor aversions. Only half of the rats were preexposed to the taste, and then an odor and plain water or an odor and a taste were paired with illness. If preexposure improves the ability of rats to utilize odors as cues for illness, then those rats given preexposure should form stronger odor aversions in the absence of taste than would rats not given the preexposure.

\section{Method}

Apparatus and Subjects. The subjects were 34 male SpragueDawley rats, weighing 160-373 g. The rats were housed and maintained as described in Experiment 2. The olfactometer described in Experiment 1 was used for all training and testing.

Procedure. Because the procedure was similar to that of Experiment 2, only the differences will be emphasized here. The rats were habituated to the olfactometer for $\mathbf{8}$ days. Half the rats were then preexposed to the sweet taste for 3 days prior to acquisition. The remaining rats were given plain water during these 3 days.

After the last preexposure day, the rats were assigned to four groups so that average consumption on the last preexposure day was similar for each group. The day after the last preexposure day was a single acquisition day consisting of a 2 (odor vs. odor/taste) $\times 2$ (preexposed vs. novel) design. Nine of the rats that had been preexposed to the taste and 9 that had not been preexposed were given odor with plain water during acquisition (Groups O-PreX and O-Nov, respectively). The remaining 8 preexposed rats and 8 nonpreexposed rats were presented with the odor and taste together (Groups OT-PreX and OT-Nov, respectively). Thirty minutes after the odor or odor and taste presentation, each rat was injected with $\mathrm{LiCl}$.

Following acquisition, the rats were returned to the habituation schedule for 1 day and then were tested for odor and taste aversions as described in Experiments 1 and 2.

Data analysis. Data collection and analysis were similar to those in Experiment 1. To analyze the acquisition, taste test, and odor test data, 2 (O vs. OT) $\times 2$ (preexposed vs. novel) ANOVAs were used. Data from 1 rat from Group OT-Nov were omitted from the analysis because the rat had consumed less than $1 \mathrm{ml}$ during acquisition. 


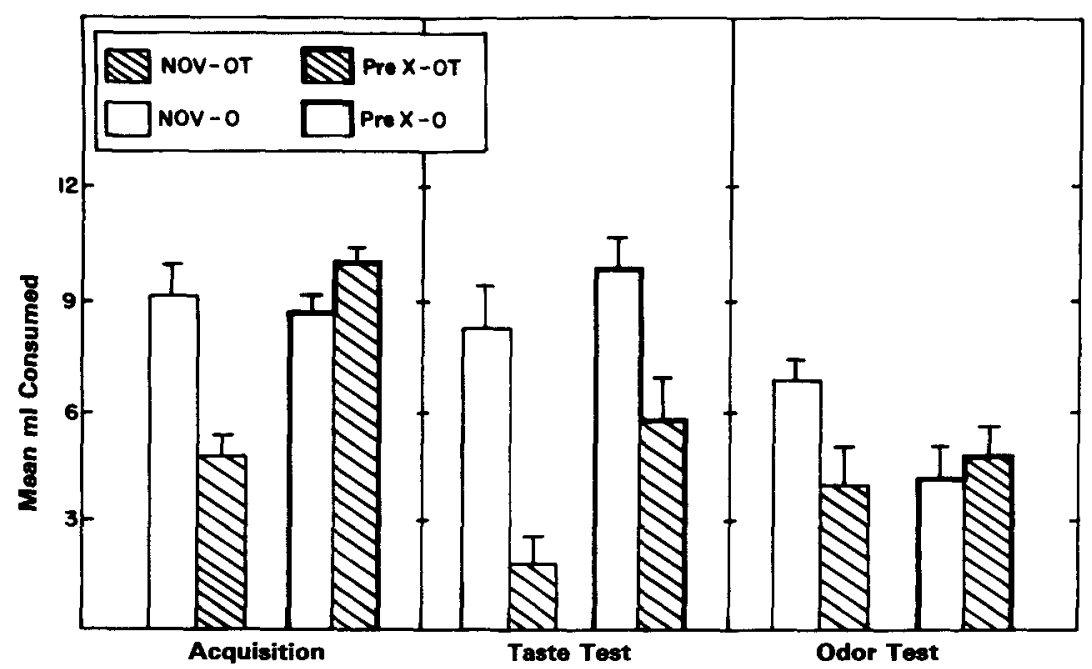

Figure 3. Experiment 3: Consumption during acquisition and during taste and odor tests is shown for the four groups. During acquisition, the group given a taste for the first time (Group Nov-O) consumed less. During the taste test, both groups that received the taste during acquisition (Groups PreX-OT and Nov-OT) showed a taste aversion, but the aversion was stronger when the taste was novel (Group Nov-OT). During the odor test, all groups showed odor aversions, although, compared with the group receiving the odor without the taste (Group Nov-O), the group that received the odor with the novel taste during acquisition (Group Nov-OT) showed a potentiated aversion. The odor aversion of the groups preexposed to the taste (Groups PreX-OT and PreX-O) was the same as that of Group Nov-OT. (Error bars represent standard errors.)

\section{Results and Discussion}

Figure 3 shows consumption during acquisition and during the odor and taste tests for each group. During acquisition, Group Nov-OT consumed less of the sweet water than the other groups. This difference was reflected in a significant prior experience (Nov vs. PreX) $\times$ acquisition stimulus (OT vs. O) interaction $[F(1,29)=21.5$, $p<.001]$. Group Nov-OT was the only group that received a novel taste during acquisition, and the reduced consumption was probably the result of neophobia. The difference indicated that the preexposure manipulation was effective.

When taste was tested, the groups that had received the taste during acquisition consumed less than those that had received only the odor $[F(1,29)=23, p<.001]$. The preexposure effect was evident from the fact that Group PreX-OT's taste aversion was less than that of Group Nov-OT. This conclusion was confirmed by a significant effect of prior experience (preexposure vs. novel) $[F(1,29)=6.4, p<.05]$.

During the odor test, a taste-potentiated odor aversion was evident. For the rats not preexposed to the taste, those given the taste during acquisition (Group Nov-OT) consumed less that those not given the taste (Group Nov-O). However, for the preexposed rats, there was no evidence of a taste-potentiated odor aversion. The odor aversion was equally strong for the two preexposed groups, whether the rats were given the odor and plain water (Group PreX-O) or the odor and taste (Group PreX-OT) during acquisition. The interaction between the stimulus presented during acquisition (OT vs. O) and prior experience (preexposure vs. novel) was close to, but did not quite reach, traditional levels of significance $[F(1,29)=$ $3.2, p=.08]$.

Experiment 3 replicated the original findings of Experiment 1 , that taste preexposure has two effects and one noneffect: reduction in neophobia, attenuation of a subsequent taste aversion, and no change in consumption in the presence of an odor that was presented with the taste prior to illness. A fourth finding of Experiment 3 was that preexposure to a taste improved the rats' capacity to utilize odors as signals for illness. Rats preexposed to tastes can learn to avoid odors paired with illness in the absence of tastes better than rats not preexposed to the tastes.

\section{GENERAL DISCUSSTON}

Exteroceptive stimuli, such as odor, presented in compound with taste, can acquire aversive properties when followed by poison (see Lett, 1984b). Classically defined exteroceptive stimuli, such as visual and auditory cues, can also be potentiated when they are paired with food cues and are followed by poison (Ellins, Cramer, \& Whitmore, 1985; Galef \& Osborne, 1978; Lett, 1984a; Morrison \& Collyer, 1974). However, at least in the case of auditory cues, the effect is observed only when the source of the noise is very close to the food source (Ellins et al., 1985) and prior experience with the noise disrupts any 
association (Ellins \& Von Kluge, in press). Although aversions are developed when exteroceptive stimuli occur with taste and are followed by illness, aversions do not as readily develop between exteroceptive stimuli and illness when the taste is absent.

These behavioral studies, supported by the neuroanatomical work described in the introduction, have been incorporated into a theory of flavor aversion learning (Garcia, Lasiter, Bermudez-Rattoni, \& Deems, 1985). According to this theory, odors are normally treated as exteroceptive cues, which are readily associated with external events such as peripheral pain but not with internal events such as illness. When presented together with taste, odors are gated into the "gut system," where they are treated as tastes. Once an odor has been gated into the gut system, it is readily associated with internal events and is less readily associated with external events.

Within the framework of this theory, the work presented here helps to define how odor is treated when presented together with taste. When presented with a preexposed taste, an odor does not take on the specific properties of the taste with which it is presented. This is indicated by the finding that taste preexposure does not affect odorillness learning. According to the theory described above, this finding suggests that the odor is gated into the gut system at a very early stage (i.e., before the taste is recognized as familiar) or that the taste is recognized as familiar before the odor is gated, but that the gating mechanism is not sensitive to preexposure effects. The results of Experiment 3 provide an alternative explanation for the results of the present series of experiments, an explanation that does not rely on potentiation and therefore does not involve the gating mechanism. Perhaps taste preexposure eliminates taste-potentiated odor aversions, but odor aversions are still apparent because the preexposure enhances the rat's capacity to learn straight odor aversions. This interpretation is supported by Experiment 3's finding that the strength of the odor aversion is the same for rats preexposed to taste whether or not the taste was present during acquisition.

This explanation is consistent with the results of other studies involving the role of taste preexposure and the potentiation of exteroceptive stimuli other than odors. In these studies, a preexposed taste was paired with lithium, and the subsequent aversion to the environmental stimuli in which the taste was paired with illness was measured (Best, Batson, Meachum, Brown, \& Ringer, 1985; Best \& Meachum, 1986). The results indicated that the capacity of a taste to potentiate an environment-illness association was reduced when the taste was preexposed. The operation of the gating mechanism may be the same for all exteroceptive stimuli, including odors; taste preexposure attenuates the capacity of the taste to potentiate these stimuli. However, since taste preexposure also improves the ability of rats to acquire nonpotentiated odorillness aversions, the attenuation of the potentiated odor aversion is masked.

\section{REFERENCES}

Bermudez-Rattoni, F., Rusiniax, K. W., \& Garcia, J. (1983). Flavor-illness aversions: Potentiation of odor by taste is disrupted by application of novocaine into amygdala. Behavioral \& Neural Biology, 37, 61-75.

Best, M. R., Batson, J. D., Meachum, C. L., Brown, E. R., \& RINGER, M. (1985). Characteristics of taste-mediated environmental potentiation in rats. Learning \& Motivation, 16, 190-209.

Best, M. R., \& Meachum, C. L. (1986). The effects of stimulus preexposure on taste-mediated environmental conditioning: Potentiation and overshadowing. Animal Learning \& Behavior, 14, 1-5.

Coburn, K. L., Garcin, J., Kiefer, S. W., Rusiniak, K. W. (1984) Taste potentiation of poisoned odor by temporal contiguity. Behavioral Neuroscience, 98, 813-819.

Eluins, S. R., Cramer, R. E., \& Whtmore, C. (1985). Taste potentiation of auditory aversions in rats: A case for spatial contiguity. Journal of Comparative Psychology, 99, 108-111.

ElliNs, S. R., \& VoN KLUGE, S. (in press). Extinction, spontaneous recovery and preexposure effects of taste-potentiated lithium chlorideinduced auditory food aversions in rats. Behavioral Neuroscience.

Galef, B. G., JR., \& OsBorne, B. (1978). Novel taste facilitation of the association of visual cues with toxicosis in rats. Journal of Comparative \& Physiological Psychology, 92, 907-916.

Garcia, J., Lasiter, P. S., Bermudez-Ratton, F., \& Deems, D. A (1985). A general theory of aversion learning. Annals of the New York Academy of Sciences, 443, 8-21.

Holder, M. D., GARCIA, J. (in press). Role of temporal order and odor intensity in taste-potentiated odor aversions. Behavioral Neuroscience.

HollaND, P. (1981). Acquisition of representation-mediated conditioned food aversions. Learning \& Motivation, 12, 1-18.

HollaND, P. (1983). Representation-mediated overshadowing and potentiation of conditioned aversions. Journal of Experimental Psychology: Animal Behavior Processes, 9, 1-13.

Holland, P., \& Forbes, D. T. (1982). Representation-mediated extinction of conditioned flavor aversions. Leaming \& Motivation, 13, 454-471.

Kalat, J. W., \& Rozrn, P. (1973). "Learned safety" as a mechanism in long-delay taste-aversion learning in rats. Journal of Comparative \& Physiological Psychology, 83, 198-207.

Kiefer, S. W., Rusiniak, K. W., \& GARCia, J. (1982). Flavor illness aversions: Gustatory neocortex ablations disrupt taste but not tastepotentiated odor cues. Journal of Comparative \& Physiological Psychology, 96, 540-548.

LETT, B. T. (1984a). Extinction of taste aversion does not eliminate taste potentiation of odor aversion in rats or color aversion in pigeons. Animal Learning \& Behavior, 12, 414-420.

LETT, B. T. (1984b). Taste potentiation in poison avoidance learning. In M. Commons, R. Herrnstein, \& A. Wagner (Eds.), Quantitative analyses of behavior: Vol. 3. Acquisition. Cambridge, MA: Ballinger.

MoRrison, G. R., \& Collyer, R. (1974). Taste-mediated conditioned aversion to an exteroceptive stimulus following LiCl poisoning. Journal of Comparative \& Physiological Psychology, 86, 51-55.

PAlmerino, C. C. (1979). Associative interactions of odor and taste in illness-induced aversions. Unpublished doctoral dissertation, University of California, Los Angeles.

Palmerino, C. C., Rusiniak, K. W., Forthman, D. L., \& Garcia, J. (1981). Comparison of noise and odor cues in potentiation by taste and shock learning. Unpublished manuscript.

Palmerino, C. C., Rusiniax, K. W., \& Garcia, J. (1980). Flavorillness aversions: The peculiar roles of odor and taste in memory for poison. Science, 208, 753-755.

REVUSKY, S., \& BEDARF, E. W. (1967). Association of illness with prior ingestion of novel foods. Science, 155, 219-220.

Rusiniak, K. W., Garcia, J., Palmerino, C. C., \& Cabral, R. J. (1983). Developmental flavor experience affects utilization of odor, not taste in toxiphobic conditioning. Behavioral \& Neural Biology, $39,160-180$. 
Rusiniak, K. W., Hankins, W. G., Garcia, J., \& Brett, L. P. (1979). Flavor-illness aversions: Potentiation of odor by taste in rats. $B e-$ havioral \& Neural Biology, 25, 1-17.

Rusiniak, K. W., Palmerino, C. C., Rice, A. G., Forthman, D. L., \& Garcia, J. (1982). Flavor-illness aversons: Potentiation of odor by taste with toxin but not shock in rat. Journal of Comparative \& Physiological Psychology, 96, 527-539.

SPEAR, N. E., KuCHARSKI, D. (1984a). Ontogenetic differences in stimulus selection during conditioning. In R. V. Kail \& N. E. Spear (Eds.), Memory development: Comparative perspectives (pp. 227-252). Hillsdale, NJ: Erlbaum.
SpEAR, N. E., KuCharsKi, D. (1984b). Ontogenetic differences in the processing of multi-element stimuli: Potentiation and overshadowing. In H. Roitblat, T. Bever, \& H. Terrace (Eds.), Animal cognition (pp. 543-568). Hillsdale, NJ: Erlbaum.

Westbrook, R. F., Bond, N. W., FeYer, A. (1981). Short- and long-term decrements in toxicosis-induced odor-aversion learning: The role of duration of exposure to an odor. Journal of Experimental Psychology: Animal Behavior Processes, 7, 362-381.

(Manuscript received July 1, 1986; revision accepted for publication October 29, 1986.) 